\title{
TREATMENT OF WASTEWATER CONTAINING DYE MIXTURE USING PYRITE CINDER IN HETEROGENEOUS FENTON PROCESS
}

\author{
Đurđa Kerkez ${ }^{1}$ (D), Milena Bečelić-Tomin ${ }^{1}$ (D), Aleksandra Kulić ${ }^{1}$ (D), \\ Dragana Tomašević Pilipović ${ }^{1}$ (D), Anita Leovac Maćerak ${ }^{1}$ (D), \\ Božo Dalmacija $^{1}$ (D), Miljana Prica ${ }^{2}$ (D) \\ ${ }^{1}$ University of Novi Sad, Faculty of Sciences, Department of Chemistry, \\ Biochemistry and Environmental Protection, Novi Sad, Serbia \\ ${ }^{2}$ University of Novi Sad, Faculty of Technical Sciences, \\ Department of Graphic Engineering and Design, Novi Sad, Serbia
}

\begin{abstract}
Dyes and pigments are important industrial chemicals. The structures of dyes can be very diverse and complex, so the treatment of wastewater containing these chemicals can be very challenging. Fenton process is particularly attractive and effective to degrade a wide range of dyes. In order to reduce the expenses related to applying these processes, the use of waste materials in the heterogeneous Fenton process, as alternative sources of catalytic iron, is recently investigated in scientific literature. In this study effluent was obtained from dye house unit of carpet factory (Serbia) and it contained the mixture of six commercial dyes. Pyrite cinder, a residue from sulfuric acid production, was also used in this process as a source of catalytic iron. Effluent decolourization rate reached $75 \%$ under optimal condition. Additionally, the research included further characterization of obtained effluent in terms of mineralization and metal leaching. A significant degree of mineralization was achieved under the applied conditions. Although, dye degradation was satisfactory, the metal content of the solutions after the process suggests that an additional treatment step, by using lime, is necessary. Results indicated that the applied waste material is effective as iron source in modified Fenton processes for treatment of effluent containing mixture of dyes.
\end{abstract}

Key words: dyes, pyrite cinder, Fenton process, decolourization, mineralization

\section{INTRODUCTION}

Textile manufacturing is one of the largest industrial producers of wastewaters, which are characterized by strong colour, highly fluctuating $\mathrm{pH}$, high chemical oxygen demand (COD), and biotoxicity. Under typical reactive dyeing conditions, not all dyes bind to the fabric; depending on the class of dye, up to $50 \%$ of the initial dye remains in the spent dye bath in its hydrolysed form, which has no affinity for the fabric and results in a coloured effluent. Dyes are known to be non-degradable under the typical aerobic conditions found in conventional biological treatment systems and adsorb very poorly biological solids, resulting in residual colour in discharged effluents (Becelic-Tomin et al, 2014), (Gozmen et al, 2009). Advanced oxidation processes (AOPs) are the most attractive technologies for dye wastewater treatment, able to oxidize quickly and non-selectively a broad range of pollutants (Chang \& Chern, 2010; Ilinoiu et al, 2013; Saravanan et al, 2014). Fenton process is particularly attractive and effective to degrade a wide range of dyes. It is also relatively cheap and easy to perform compared to other AOPs processes. On the other hand, classical Fenton process implies continuous loss of iron ions due to formation of solid sludge and also a heavy load of counter ions. This can be avoided by employing heterogeneous Fenton processes. A great deal of interest has developed in the degradation of different dyes by modifying the Fenton system and/or introducing novel alternative iron sources. Numerous researchers (Dukkancl et al, 2010), (Kasiri et al, 2008), (Kusic et al, 2007), (Wu et al, 2013) have shown that $\mathrm{H}_{2} \mathrm{O}_{2}$ can oxidize organic pollutants in the presence of solid catalysts which contain iron. One of the potential waste materials that can be used as catalytic iron source is Fenton process is pyrite cinder. Pyrite cinder $(\mathrm{PC})$ is generated in sulfuric acid production, and a high content of iron oxide of this type of waste, in the form of hematite and magnetite, is the basis for the research regarding the possibility of its use as a source of catalytic iron in the modified heterogeneous Fenton processes in wastewater treatment. In this paper optimum operating conditions were established in order to achieve the highest decolourization efficiency of textile industry effluent when using PC. Also the characterization of the obtained effluent in terms of leached metals and arsenic as well as the determination of mineralization efficiency was performed. 


\section{METHODS}

Textile industry effluent was obtained from dye house unit of carpet factory (Serbia) and it contained the mixture of six commercial dyes: Tectilon Yellow 3R (317 mg/l); Tectilon Red 2B (182 mg/l); Tectilon Blue 4R (179 mg/l); Maxilon Yellow GL (5.2 mg/l); Maxilon Red 3GLN (9.3 mg/l) i Maxilon Blue TL (9.3 mg/l), as well as different thickeners and additives in total concentration of $12.5 \mathrm{~g} / \mathrm{l}$. It was characterized by using standard laboratory procedures. The PC used in this work was a remnant after the combustion of pyrite in the production of sulphuric acid in the chemical industry in Serbia. All solutions were prepared with deionised water. All experiments were conducted at room temperature $(25 \pm 0.5 \circ \mathrm{C})$. The relative standard deviations (\% RSD) obtained $(n=3)$ were below $10 \%$. The experiments were conducted on a jar test apparatus (FC6S Velp Scientifica, Italy), where reactive mixtures with 0.25 I volumes were continually mixed in 1 I laboratory cups, at $150 \mathrm{rpm}$. The experiments were performed in the following manner: firstly, the appropriate PC dosage was added to the model dye solution, which was followed by $\mathrm{pH}$ adjustment to the desired value and the addition of the required amount of $\mathrm{H}_{2} \mathrm{O}_{2}$. Decolourization of the textile industry effluent was monitored by absorbance $(A)$ at $\lambda \max =411 \mathrm{~nm}$ for (UV/VIS spectrophotometer, Shimadzu, Japan). The efficiency of dye decolourization was obtained by the application of the following formula (1):

Decolourization efficiency $[\%]=\left(\left(\mathrm{A}_{0}-\mathrm{A}_{\mathrm{t}}\right) / \mathrm{A} 0\right) * 100 \%$

Where: $A_{0}$ - represents the initial absorbance of dye solution and $A_{t}$ - represents absorbance of dye solution after a certain time $t$.

Decolourization kinetic analysis was determined by using mathematical model of the author (Behnajady, Modirshahla, Ghanbary et al, 2007). Characterization of the treated effluent in terms of leached metals and arsenic was performed before and after adjusting the $\mathrm{pH}$ to 7.5-8 by atomic absorption spectrometry AAS (Perkin Elmer AAnalyst тм 700). Determination of mineralization obtained effluents was performed by determination of total organic carbon (TOC) using Elementar Liqui Germany Toc analyzer and chemical oxygen demand (COD) using the standard method.

\section{RESULTS AND DISCUSSION}

The effect of PC concentration on the decolourization efficiency of textile industry effluent is shown in Figure 1a. Increasing concentrations of PC lead to an increase in the concentration of iron ions in the Fenton process, and on the other hand to the available surface on which the reaction takes place, which causes a greater production of $\mathrm{HO}$ • radicals to a certain amount (Daud \& Hameed, 2010). The decolourization efficiency of textile industry effluent at higher concentrations of PC (40 and $80 \mathrm{~g} / \mathrm{l}$ ) was satisfactory ranging between 74.5 and $78.3 \%$.

As further amount increase of PC did not significantly affect the decolourization efficiency, the following experiments used the PC concentration $40 \mathrm{~g} / \mathrm{l}$.

Figure $1 b$ shows the decolourization efficiency in the dependence of the applied initial hydrogen-peroxide concentration. The highest decolourization efficiency was obtained at an initial concentration of $50 \mathrm{mM}$. The effect of the decolourization efficiency reduction at higher $\mathrm{H}_{2} \mathrm{O}_{2}$ concentrations can be explained by the phenomenon in which molecules of $\mathrm{H}_{2} \mathrm{O}_{2}$ exhibit the "scavenging" effect towards $\mathrm{HO}$ - and lead to the formation of less reactive species such as $\mathrm{HO}_{2}$ (Hassan \& Hameed, 2011).

Changing the $\mathrm{pH}$ values can have an influence on the heterogeneous Fenton reactions which take place on the catalyst surface (Zhao \& Hu, 2008). The results indicate that the Fenton process with the use of PC as a source of iron, similar to the conventional Fenton process, shows the highest efficiency for $\mathrm{pH}=3$, and the downward trend in the decolourization efficiency with increasing the $\mathrm{pH}$ values (Figure 1c) (Arslan-Alaton \& Teksoy, 2007). The acidity of the PC itself contributed to the reduction of the dye solution $\mathrm{pH}$. 


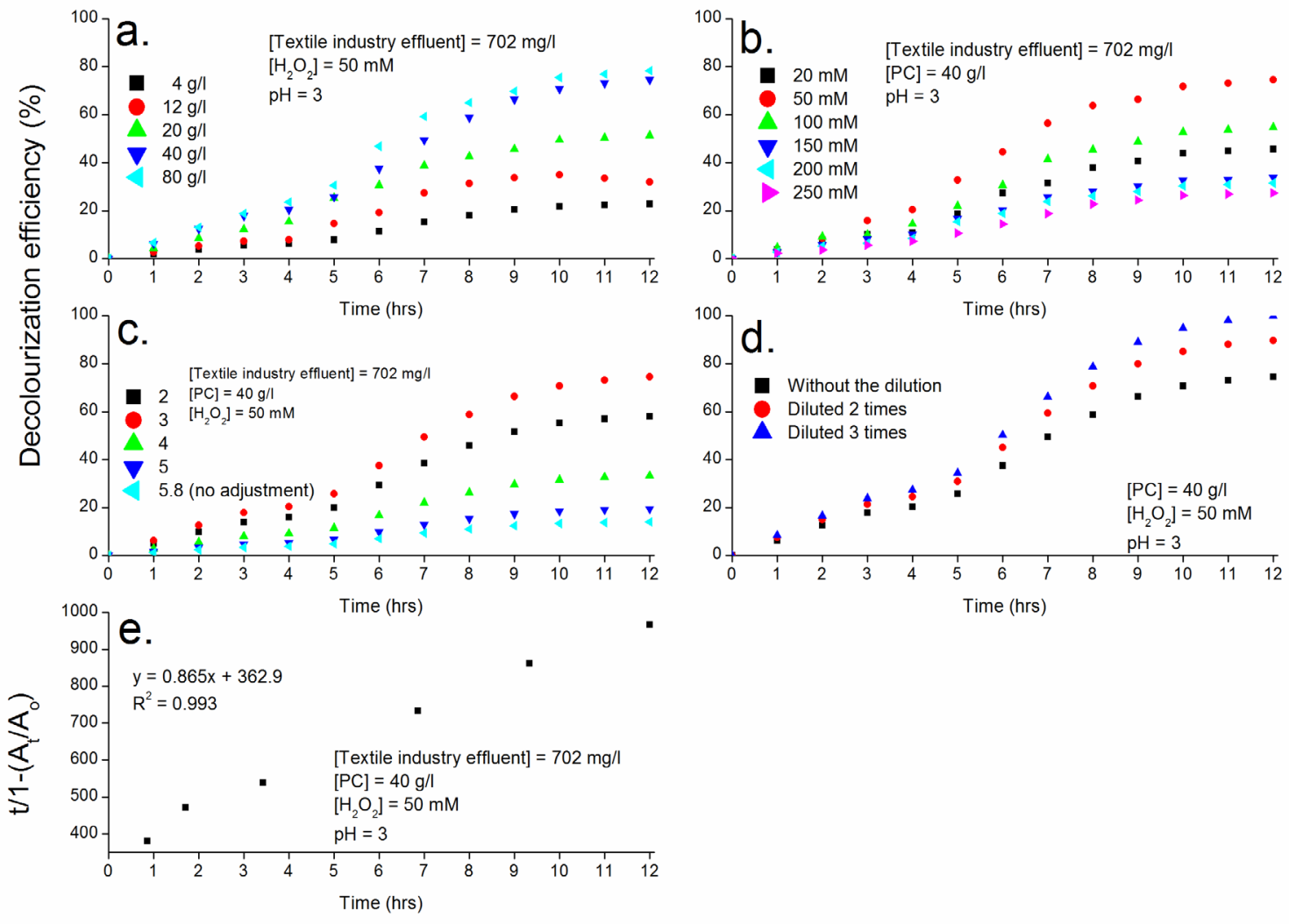

Figure 1: Optimization of textile industry effluent solution decolourization, a. Effect of PC dosage; b. Effect of $\mathrm{H}_{2} \mathrm{O}_{2}$ concentration; c. Effect of initial solution pH; d. Effect of initial dye concentration; e. Kinetics

The effect of the initial concentration of dye on the decolourization efficiency is given in Figure $1 \mathrm{~d}$. It can be seen that with the increase of the dye concentration there is a reduction in the decolourization efficiency. The increase in concentration implies an increase in the number of dye molecule but with the same amount of $\mathrm{OH} \bullet$ radicals present, which causes this effect. Also, in the heterogeneous Fenton processes, reactions are partially carried out on the surface of the catalyst, so that when the dye concentration is high, the number of active sites is reduced due to the competitive adsorption of dye molecule (Chen et al, 2008).

Regarding the kinetic analysis, the resulting value of the derived coefficients indicate that using PC as a source of iron in a heterogeneous Fenton process takes longer period of time to achieve effective decolourization in comparison to a homogeneous Fenton processes (Figure 1e.). Similar studies have also shown that Fenton treatment of wastewater, including those from the textile industry, requires longer reaction time to achieve high efficiency primarily due to the very complex composition and high concentration of different colours and additives (Galeano et al, 2011).

In this research the untreated PC, with a high content of other metals, was used. Therefore metal leaching in dye solution after the applied Fenton process was investigated, when the $\mathrm{pH}$ value of the examined effluents after the treatment was 3. $\mathrm{pH}$ value and the metal content indicated the necessity of an additional step for the treatment of effluents in order to remove residual leached metals. Namely, lead, copper, chromium and cadmium were leached above the emission limit values according to "Official Gazette", 67, 2011, [14]. Among the leading technologies, that are recommended and used for the removal of potentially toxic substances from the effluent, precipitation is the most widely used for the removal of metals from industrial effluents. In this experiment, we used the lime, which was added to treated effluents, while maintaining the $\mathrm{pH}$ value in the range $7.5-8$, in order to meet the requirements [14]. At the same time, this value is close to the $\mathrm{pH}$ range which helps to minimize the solubility of the hydroxides of most metals.

It can be concluded that the addition of lime in the reaction mixtures after the Fenton process contributed to a significant reduction in the metal content in the investigated solutions. After adjusting the $\mathrm{pH}$ by using lime, the emission limit values for metals are met. 
The mineralization level of the studied heterogeneous Fenton effluent after the treatment is usually determined by measuring the degree of removal of total organic carbon (TOC), and the degree of reduction of chemical oxygen demand (COD). Removal of COD depends entirely on the complete mineralization of the dye molecule, while the reduction in TOC values is primarily attributed to the fragmentation of highly-complex structures of dye molecules on relatively simpler organic fragments, such as carboxylic acids, aldehydes, ketones, alcohols etc. These parameters were measured in the initial solution and in effluent after the Fenton treatment when applying optimal conditions (Table 1).

Table 1: COD and TOC values before and after application of the heterogeneous Fenton process

\begin{tabular}{|l|l|l|l|}
\hline \multicolumn{2}{|c|}{} & $\begin{array}{l}\mathrm{COD} \\
\mathrm{mg} \mathrm{O}_{2} / \mathrm{I}\end{array}$ & $\begin{array}{l}\mathrm{TOC} \\
\mathrm{mg} \mathrm{C} / \mathrm{I}\end{array}$ \\
\hline \multirow{2}{*}{$\begin{array}{l}\text { Textile } \\
\text { industry } \\
\text { effluent }\end{array}$} & Before treatment & 7893 & 2500 \\
\cline { 2 - 4 } & After treatment & 4110 & 1760 \\
\cline { 2 - 4 } & \% Removal & 47.9 & 29.6 \\
\hline
\end{tabular}

\section{CONCLUSIONS}

PC has been proved to be a superior catalyst for decolourization of textile industry effluent in a modified Fenton process $75 \%$ of decolourization was achieved. Also a significant degree of mineralization was achieved under the applied conditions. Although, dye degradation was satisfactory, the metal content of the solutions after the process suggests that an additional treatment step, by using lime, is necessary to remove the remaining metals from the water. Overall using this waste material as an alternative source of catalytic material for dye degradation is a cost-effective method for making textile wastewater viable for further treatment and minimizing possible negative environmental effects.

\section{ACKNOWLEDGMENTS}

The research was funded by the Ministry of Education, Science and Technological Development (Project III43005).

\section{REFERENCES}

[1] Arslan-Alaton, I., Teksoy, S.: "Acid dyebath effluent pretreatment using Fenton's reagent: Process optimization, reaction kinetics and effects on acute toxicity", Dyes and Pigments, 73, 31-39, 2007. doi: 10.1016/j.dyepig.2005.09.027

[2] Becelic-Tomin, M., Dalmacija, B., Rajic, Lj., Tomasevic, D., Kerkez, Dj., Watson, M., Prica, M.: "Degradation of Anthraquinone Dye Reactive Blue 4 in Pyrite Ash Catalyzed Fenton Reaction", The Scientific World Journal, 2014. doi: 10.1155/2014/234654

[3] Behnajady, MA., Modirshahla, N., Ghanbary, F.: "A kinetic model for the decolorization of C.I. Acid Yellow 23 by Fenton process", Journal of Hazardous Materials, 148(1-2), 98-102, 2007. doi: 10.1016/j.jhazmat.2007.02.003

[4] Chang, MW., Chern, JM.: "Decolorization of peach red azo dye, HF6 by Fenton reaction: initial rate analysis", Journal of the Taiwan Institute of Chemical Engineers, 41(2), 221-228, 2010. doi: 10.1016/j.jtice.2009.08.009

[5] Chen, A., Ma, X., Sun, H.: "Decolorization of KN-R catalyzed by Fe-containing Y and ZSM-5 zeolites", Journal of Hazardous Materials, 156(1-3), 568-75, 2008. doi: 10.1016/j.jhazmat.2007.12.059

[6] Daud, NK., Hameed, BH.: "Decolorization of Acid Red 1 by Fenton-like process using rice husk ash-based catalyst", Journal of hazardous materials, 176(1-3), 938-44, 2010. doi: 10.1016/j.jhazmat.2009.11.130

[7] Dukkancı, M., Gunduz, G., Yılmaz, S., Yaman, YC., Prikhodko, RV., Stolyarova, IV.: "Characterization and catalytic activity of CuFeZSM-5 catalysts for oxidative degradation of Rhodamine 6G in aqueous solutions", Applied Catalysis B Environmental, 95(3-4), 270-278, 2010. doi: 10.1016/j.apcatb.2010.01.004 
[8] Galeano, AL., Vicente, MA., Gil, A.: "Treatment of municipal leachate of landfill by Fenton-like heterogeneous catalytic wet peroxide oxidation using an Al/Fe-pillared montmorillonite as active catalyst", The Chemical Engineering Journal, 178, 146-153, 2011. doi: 10.1016/j.cej.2011.10.031

[9] Gozmen, B., Kayan, B., Gizir, A.M., Hesenov, A.: "Oxidative degradations of reactive blue 4 dye by different advanced oxidation methods", Journal of Hazardous Materials, 168, 129-136, 2009. doi: 10.1016/j.jhazmat.2009.02.011

[10] Hassan, H., Hameed, BH.: "Fe-clay as effective heterogeneous Fenton catalyst for the decolorization of Reactive Blue 4", The Chemical Engineering Journal, 171(3), 912-918, 2011.

[11] Ilinoiu, EC., Pode, R., Manea, F., Colar, LA., Jakab, A., Orha, C., Ratiu, C., Lazau, C., Sfarloaga, P.: "Photocatalytic activity of a nitrogen-doped $\mathrm{TiO}_{2}$ modified zeolite in the degradation of Reactive Yellow 125 azo dye", Journal of the Taiwan Institute of Chemical Engineers, 44(2), 270-278, 2013. doi: 10.1016/j.jtice.2012.09.006

[12] Kasiri, MB., Aleboyeh, H., Aleboyeh, A.: "Degradation of Acid Blue 74 using Fe-ZSM5 zeolite as a heterogeneous photo-Fenton catalyst", Applied Catalysis B Environmental, 84(1), 9-15, 2008.

[13] [Kusic, H., Loncaric Bozic, A., Koprivanac, N., Papic, S.: "Fenton type processes for minimization of organic content in coloured wastewaters. Part II: Combination with zeolites", Dyes and Pigments, 74(2), 388-395, 2007. doi: 10.1016/j.dyepig.2006.01.050

[14] Ministry of Energy, Development and Environmental Protection of Republic of Serbia, "Regulation on limit values of pollutants in water and deadlines for their achievement", Official Gazette, 67 (2011), 13-41

[15] Saravanan, R., Gupta, VK., Narayanan, V., Stephen, A.: "Visible light degradation of textile effluent using novel catalyst $\mathrm{ZnO} / \mathrm{g}-\mathrm{Mn}_{2} \mathrm{O}_{3}$ ", Journal of the Taiwan Institute of Chemical Engineers, 45(4), 1910-1917, 2014. doi: 10.1016/j.jtice.2013.12.021

[16] Wu, J., Lin, G., Li, P., Yin, W., Wang, X., Yang, B.: "Heterogeneous Fenton-like degradation of an azo dye reactive brilliant orange by the combination of activated carbon-FeOOH catalyst and $\mathrm{H}_{2} \mathrm{O}_{2}$ ", Water Science \& Technology, 67(3), 572-578, 2012. doi: 10.2166/wst.2012.596

[17] Zhao, Y., Hu, J.: "Photo-Fenton degradation of 17b-estradiol in presence of a-FeOOHR and $\mathrm{H}_{2} \mathrm{O}_{2}$ ", Applied Catalysis B Environmental, 78(3-4), 250-258, 2008. doi: 10.1016/j.apcatb.2007.09.026

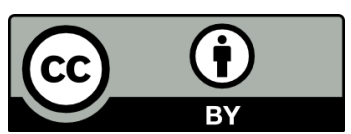

(C) 2018 Authors. Published by the University of Novi Sad, Faculty of Technical Sciences, Department of Graphic Engineering and Design. This article is an open access article distributed under the terms and conditions of the Creative Commons Attribution license 3.0 Serbia (http://creativecommons.org/licenses/by/3.0/rs/). 